\title{
Tradução e acessibilidade: Audiodescrição e legendagem para surdos e ensurdeci- dos como campos de atuação para tradutores ${ }^{1}$
}

\author{
Marcela Belizário Cabaz e Patrícia Viana Belam*
}

\section{Introdução}

Nos últimos tempos, discussões e soluções para tornar todas as esferas da sociedade acessíveis a pessoas com deficiências em geral vêm crescendo acentuadamente. $\mathrm{O}$ conceito de acessibilidade mudou muito e, aos poucos, as pessoas vêm percebendo que uma sociedade acessível está além da adaptação do ambiente físico. Acessibilidade é um Direito Humano e “[...] significa conseguir a equiparação de oportunidades em todas as esferas da vida" (Gil, 2006). Para que a sociedade se torne acessível como um todo, fazendo com que todas as pessoas tenham acesso à educação, à cultura, ao lazer e à comunicação, é necessário que profissionais em todas essas esferas tenham consciência da importância de tornar um recurso, um produto ou um ambiente acessível a pessoas com qualquer tipo de deficiência.

No que diz respeito à acessibilidade comunicacional, podemos destacar os recursos de audiodescrição e legendagem para surdos e ensurdecidos. Ambas as atividades surgiram a fim de tornar produtos audiovisuais acessíveis a pessoas com deficiência visual e auditiva. Hoje, os recursos beneficiam milhares de pessoas por todo o mundo, inclusive pessoas com deficiência intelectual.

\footnotetext{
1 Este artigo é decorrente do trabalho de conclusão de curso de Marcella Belizário Cabaz, sob a orientação e coautoria da profa. Dra. Patrícia Viana Belam, apresentado em dezembro de 2015 como requisito para a graduação no curso de Letras-Tradutor da Universidade do Sagrado Coração, Bauru-SP.

* Marcella Belizário Cabaz é graduada em Letras-Tradutor pela Universidade do Sagrado Coração (USC Bauru, 2015). Patrícia Viana Belam, doutora em Ciências e mestra em Estudos Linguísticos, é docente na USC.
} 
CABAZ e BELAM, Tradução e acessibilidade: audiodescrição e legendagem para surdos e ensurdecidos como campos de atuação para tradutores

A audiodescrição (AD) é um recurso que possibilita que pessoas com deficiência visual tenham acesso a peças de teatro, filmes, programas de televisão, e até óperas e apresentações de dança, através da descrição dos componentes visuais relevantes na cena. Segundo Motta (2008), essa prática "é a arte de transformar aquilo que é visto no que é ouvido, o que abre muitas janelas do mundo para as pessoas com deficiência visual".

Já a legendagem para surdos e ensurdecidos (LSE), também conhecida como closed caption, permite que pessoas com deficiência auditiva consigam, através da legenda, ter acesso a todos os detalhes sonoros que não seriam possíveis de serem entendidos devido à deficiência. Segundo Selvatini (2011), detalhes como identificação dos falantes e explicitação de efeitos sonoros como campainha soando, porta batendo, música tocando etc., não são inseridos numa legenda para o público ouvinte (ou legenda aberta), o que dificulta a compreensão de uma pessoa com deficiência auditiva.

Ambas as atividades são relativamente novas e ainda estão sendo estudadas e aperfeiçoadas. Devido a esse fato, ainda não há uma formação obrigatória para que se possa exercê-las, permitindo que qualquer pessoa que tenha interesse pelas atividades possa executá-las. No entanto, isso não quer dizer que sejam atividades simples e que qualquer pessoa tenha competência para desenvolvê-las.

Mesmo a formação não sendo obrigatória na prática dessas atividades, nota-se que o profissional de tradução vem se inserindo nessa área, na produção de materiais acessíveis quanto no meio acadêmico, desenvolvendo pesquisas, ministrando palestras e contribuindo para a formação de novos profissionais. Na realidade, a própria tradução já poderia ser vista como uma atividade que envolve acessibilidade, pois permite que pessoas que não dominam certo idioma tenham acesso a diversos tipos de materiais que são traduzidos. Como cita Díaz-Cintas (2005, p. 4 apud Franco; Araújo, 2011, p. 4) "se o desafio é uma barreira linguística ou sensorial, o objetivo do processo tradutório é exatamente o mesmo: facilitar o acesso a uma fonte de informação e entretenimento anteriormente hermética".

O presente estudo justifica-se diante do aumento da demanda por trabalhos nessas áreas, visto que a acessibilidade torna-se um tema cada vez mais recorrente nos dias atuais. Além disso, por serem atividades no- 
CABAZ e BELAM, Tradução e acessibilidade: audiodescrição e legendagem para surdos e ensurdecidos como campos de atuação para tradutores

vas, carecem de pesquisa, principalmente no que diz respeito à associação das mesmas com os estudos de tradução. Nessa perspectiva, este trabalho tem como objetivo fazer um levantamento do panorama geral das atividades de AD e LSE atualmente, assim como analisar as competências necessárias para se atuar nessas áreas e os desafios encontrados no dia-a-dia do profissional, a fim de relacionar a prática da tradução com ambas as atividades mencionadas e verificar quais as competências necessárias ao tradutor para que esteja apto a trabalhar com as mesmas.

A pesquisa é de natureza qualitativa e de cunho bibliográfico e exploratório. Através de estudos na área de acessibilidade, AD, LSE e competências do tradutor e utilizando um questionário como instrumento de coleta de dados para análise, o qual continha 8 questões diretas sobre as atividades de AD e LSE, sendo enviado a 5 profissionais que atuam nas áreas mencionadas, foi feito um levantamento das principais características dessas atividades, dos desafios encontrados no dia-a-dia e das competências necessárias para atuar nessas atividades.

A fim de mostrarmos a relação entre a tradução e as atividades de AD e LSE, além da inserção do profissional da tradução nesse campo, apoiamo-nos em conceitos sobre acessibilidade definidos por Leis e Portarias brasileiras, assim como Órgãos e Secretarias que trabalham em prol da pessoa com deficiência. Também utilizamos como base a teoria de Jakobson (1959) sobre tradução intersemiótica; de Franco e Araújo (2011) sobre tradução audiovisual; de Hurtado Albir (2005), Arrojo (2007) e Pagano (2013) sobre as competências do tradutor. Já nas definições das atividades de AD e LSE, utilizamos como teoria artigos e livros escritos por profissionais que trabalham com essas atividades, como Motta (2008), Franco (2008), Franco e Silva (2010), Motta e Romeu Filho (2010), Araújo, Vieira e Monteiro (2013), entre outros.

\section{Tradução audiovisual}

Abordamos, inicialmente, a definição e os estudos sobre a tradução audiovisual (TAV), a qual abrange diversas modalidades, como a audiodescrição (AD) e a legendagem para surdos e ensurdecidos (LSE). 
CABAZ e BELAM, Tradução e acessibilidade: audiodescrição e legendagem para surdos e ensurdecidos como campos de atuação para tradutores

Segundo Franco e Araújo (2011), o interesse pela TAV nos Estudos da Tradução começou na década de 1980, atingindo seu auge na década de 1990. No início, era chamada de screen translation, devido aos primeiros estudos na área, que faziam referência ao termo film translation ou "tradução de filmes" porque enfatizavam o cinema. Mas, com o avanço dos estudos sobre TAV, e desde o final dos anos 1980, quando o VHS se tornou popular e a atenção se voltou para a tradução realizada nesse meio, o termo "tradução audiovisual" (TAV) ou audiovisual translation (AVT) passou a vigorar e percebeu-se que definir esta prática como "tradução de filmes" ou "tradução multimídia", seria muito limitador. Assim,

Díaz Cintas deixa claro que o meio audiovisual inclui todos os espaços onde há um sinal acústico e um sinal visual, independentemente de ser transmitido através de uma tela (que pode ser ao vivo ou não) ou de um palco (sempre ao vivo). (Franco; Araújo, op. cit., p. 3).

Os tipos de TAV são muitos e podem ser listados como: legendagem interlinguística ou legenda aberta, legendagem bilíngue, dublagem, dublagem intralingual, interpretação consecutiva, interpretação simultânea, interpretação de sinais, voice-over, comentário livre, tradução à prima vista ou simultânea, produção multilinguística, legendagem intralinguística ou closed caption, tradução de roteiro, legendagem ao vivo ou em tempo real, supra-legendagem ou legendagem eletrônica e audiodescrição (Franco; Araújo, op. cit.).

A LSE já se enquadra na definição de TAV, pois ela é transmitida através de uma tela, seguindo parâmetros próximos aos da legenda aberta, destinada ao público ouvinte. Já a AD nem sempre é transmitida no cinema ou na televisão, como é o caso de espetáculos de dança, peças de teatro, exposições de arte etc., o que não a definia - no antigo conceito - como uma TAV. O que levou essa e outras técnicas, como a interpretação, a serem aceitos como TAV foi "o fato de que esses novos recursos se caracterizavam não pela tradução entre línguas, mas entre meios semióticos diferentes" (Franco; Araújo, op. cit., p. 4). 
CABAZ e BELAM, Tradução e acessibilidade: audiodescrição e legendagem para surdos e ensurdecidos como campos de atuação para tradutores

\section{Tradução intersemiótica}

Para abordarmos esse assunto, apoiamo-nos, principalmente, na teoria de Jakobson (1959) sobre os três tipos de interpretação de um signo verbal tradução intralingual, tradução interlingual e tradução intersemiótica, assim definidas:

1) Tradução intralingual ou reformulação é uma interpretação de signos verbais por meio de outros signos na mesma língua.

2) Tradução interlingual ou tradução propriamente dita é a interpretação de signos verbais por meio de signos em outra língua.

3) Tradução intersemiótica ou transmutação é a interpretação de signos verbais por meio de sistemas de signos não-verbais. (Jakobson, op. cit., p. 233, tradução nossa).

Em nosso estudo, utilizaremos, principalmente, a última modalidade definida pelo teórico russo - a tradução intersemiótica. Esta tem relação com teorias da semiótica, ciência geral dos símbolos, que estuda a produção, transmissão, substituição e interpretação de mensagens formadas de um ou mais signos. "Ambos os estudos de tradução e semiótica abordam aspectos da comunicação e ambas se interessam pelo uso, interpretação e manipulação de mensagens ou textos, ou seja, de signos." (Gorlée, 1994, p. 11, tradução nossa).

Jakobson (op. cit., p. 233), que, segundo Gorlée (op. cit.), deve ser considerado o criador do enfoque semiótico na tradução, afirma que "o tradutor recodifica e transmite uma mensagem recebida a partir de outra fonte. Sendo assim, a tradução envolve duas mensagens equivalentes em dois signos diferentes".

As atividades de AD e LSE se inserem, portanto, na definição de tradução intersemiótica, pois ambas as atividades tratam de uma recodificação de signos não verbais em signos verbais, ou seja, fazem uma transmutação entre dois meios distintos. Por um lado, a AD transforma a imagem em signos verbais e por outro, a LSE transforma o som em signos visuais. 
CABAZ e BELAM, Tradução e acessibilidade: audiodescrição e legendagem para surdos e ensurdecidos como campos de atuação para tradutores

\title{
4. Acessibilidade audiovisual
}

Segundo definição presente na Portaria n 310, de 27 de junho de 2006, do Ministério das Comunicações, acessibilidade

\begin{abstract}
é a condição para utilização, com segurança e autonomia, dos serviços, dispositivos, sistemas e meios de comunicação e informação, por pessoa com deficiência auditiva, visual ou intelectual. (Brasil, 2006).
\end{abstract}

Os dados do Censo 2010, realizado pelo Instituto Brasileiro de Geografia e Estatística (IBGE, 2010) - último Censo realizado com estimativa do número de pessoas com deficiência no Brasil - apontaram que 45.606.048 de brasileiros, $23,9 \%$ da população total, têm algum tipo de deficiência visual, auditiva, motora e mental ou intelectual. Desse total, 18,6\% apresentaram deficiência visual, 5,10\% apresentaram deficiência auditiva e 1,40\% apresentou deficiência mental ou intelectual.

"Esse grande número de indivíduos encontra-se excluído da experiência de assistir a um filme no cinema, um programa de TV, uma peça de teatro ou um espetáculo de dança em sua forma mais completa [...]" (Franco, 2008). Para que sejam inseridos na sociedade como um todo, esses indivíduos necessitam de alternativas que garantam uma acessibilidade audiovisual.

No conceito de acessibilidade pela Secretaria Nacional de Promoção dos Direitos da Pessoa com Deficiência (Acessibilidade, s.d.), é dito que a mesma deve estar presente nos espaços, no meio físico, no transporte, na informação e comunicação, inclusive nos sistemas e tecnologias da informação e comunicação.

Nessa perspectiva, portanto, encontram-se a AD e a LSE, atividades que permitem que pessoas com deficiência auditiva, visual - e até intelectual - consigam desfrutar e ter acesso a todos os meios de comunicação e entretenimento.

\section{Audiodescrição}

Segundo Franco e Araújo (2011), a AD é a tradução das impressões visuais de um objeto em palavras, seja ele um filme, uma obra de arte, uma peça de 
CABAZ e BELAM, Tradução e acessibilidade: audiodescrição e legendagem para surdos e ensurdecidos como campos de atuação para tradutores

teatro, um espetáculo de dança ou um evento esportivo e esta atividade tem como objetivo tornar esses produtos acessíveis a pessoas com deficiência visual ou baixa visão.

$\mathrm{O}$ site Audiodescrição (O que..., s.d.) define esta atividade como uma

[...] descrição clara e objetiva de todas as informações que compreendemos visualmente e que não estão contidas nos diálogos, como, por exemplo, expressões faciais e corporais que comuniquem algo, informações sobre o ambiente, figurinos, efeitos especiais, mudanças de tempo e espaço, além da leitura de créditos, títulos e qualquer informação escrita na tela.

Motta (2008) diz que "a audiodescrição traz a formalidade para algo que era, anteriormente, feito informalmente, graças à sensibilidade e boa vontade de alguns", pois a prática de se descrever o mundo visual para pessoas não-videntes é imemorial, mas, enquanto atividade técnica e profissional, a AD nasceu em meados da década de 70 nos Estados Unidos, mas somente foi utilizada em 1981, no Arena Stage Theatre, em Washington DC (Franco; Silva, 2010).

No Brasil, esse recurso chegou um pouco mais tarde, em 2003, e foi utilizado em público pela primeira vez no Festival Assim Vivemos, um festival internacional de filmes sobre deficiência. Em 2005, o filme "Irmãos de Fé", primeiro filme audiodescrito no país, foi lançado em DVD (Franco; Silva, op. cit.).

\begin{abstract}
A AD é um dos recursos utilizados para garantir a inserção do público que possui algum tipo de deficiência visual ou intelectual em diversos meios de comunicação audiovisual. É uma atividade de mediação linguística, uma modalidade de tradução intersemiótica, que transforma o visual em verbal, abrindo possibilidades maiores de acesso à cultura e à informação, contribuindo para a inclusão cultural, social e escolar. Além das pessoas com deficiência visual, a audiodescrição amplia também o entendimento de pessoas com deficiência intelectual, idosos e disléxicos. (Motta; Romeu Filho, 2010, p. 11).
\end{abstract}

Como citado anteriormente, a $\mathrm{AD}$ é considerada um tipo de tradução intersemiótica, conceito que Jakobson (1959, p. 233) - com seus três ti- 
CABAZ e BELAM, Tradução e acessibilidade: audiodescrição e legendagem para surdos e ensurdecidos como campos de atuação para tradutores

pos de interpretação de um signo verbal - tradução intralingual, interlingual e intersemiótica - definiu como "[...] interpretação dos signos verbais por meio de sistemas de signos não-verbais", ou seja, a "tradução de imagens em palavras [...] onde o signo visual é transposto para o signo verbal" (Franco, 2008). Além disso, trata-se, também, de uma tradução intralingual.

O Art. $2^{\underline{o}}$ do Projeto de Lei $\mathrm{n}^{\circ} 5.156$ (Brasil, 2013), que dispõe sobre a regulamentação do exercício da profissão de audiodescritor, lista as atribuições do profissional, sendo a primeira "planejar, preparar e narrar roteiro de audiodescrição conforme os requisitos aplicáveis a todas as produções audiodescritivas". Sendo assim, cabe ao audiodescritor-roteirista o planejamento e a preparação do roteiro de $\mathrm{AD}$, e ao audiodescritor-locutor, a narração desse roteiro. As duas funções não precisam necessariamente ser feitas pela mesma pessoa.

$\mathrm{O}$ audiodescritor-roteirista deve iniciar seu trabalho pela apreciação do produto audiovisual, para que haja a compreensão do contexto e uma análise das imagens que serão audiodescritas. Um produto audiovisual pode ter espaços muito curtos ou muito longos entre as falas. Em ambos os casos, é muito importante que o profissional tenha sensibilidade para escolher as melhores palavras para descrever as imagens. O roteiro da AD deve seguir o ritmo do produto audiovisual, não se sobrepondo ao mesmo. Além disso, é imprescindível que o audiodescritor-roteirista marque os tempos de entrada da audiodescrição de forma clara e destacada, para que a AD se encaixe entre as falas do produto audiovisual e a fim de auxiliar o trabalho do audiodescritor-locutor (Franco, 2008).

\section{Legendas para surdos e ensurdecidos}

A LSE, ou closed caption (legenda oculta ou fechada) em inglês, é descrita pelo Centro de Produção de Legendas (Sobre, s.d.), produtora pioneira no Brasil na produção do closed caption offline, como um sistema de transmissão de legenda criado para possibilitar que as pessoas com deficiência auditiva tenham acesso à comunicação veiculada na televisão, em vídeo e DVD. Segundo o Centro, existem dois tipos de legenda oculta e, portanto, tecnologias distintas para a sua produção: "online ou em tempo real, recomendada para programas ao vivo, jornalísticos, esportivos etc., sendo esta pro- 
CABAZ e BELAM, Tradução e acessibilidade: audiodescrição e legendagem para surdos e ensurdecidos como campos de atuação para tradutores

duzida por meio da estenotipia ou softwares de reconhecimento de voz e offline ou pós-produzida, recomendada para programas gravados, filmes, novelas etc., que faz uso de softwares específicos."

A LSE, como conhecida atualmente, tem raízes nos anos 1970/1980, quando dois sistemas, que permitiam a inserção de legendas fechadas na televisão, foram simultaneamente criados nos EUA e no Reino Unido. Porém, como a LSE não é oferecida somente na televisão, mas também no cinema, em DVDs, na Internet, em videogames etc., sua história não acompanha essas duas práticas pioneiras (Neves, 2005).

Sob a perspectiva dos conceitos de Jakobson (1959), abordada anteriormente, a LSE, além de ser uma tradução intersemiótica, transformando sons (signos não-verbais) em signos verbais, também “[...] pode ser uma tradução intralingual, ou seja, de uma fala em uma língua para um texto na mesma língua, ou interlingual - com as falas em uma língua e o texto em outra" (Selvatini, 2011, p. 10).

As LSEs possuem características específicas que as diferem das legendas abertas - destinadas ao público ouvinte. A primeira é a identificação dos falantes. Quando uma LSE aparece, a pessoa que proferiu aquela sentença é identificada por seu nome em colchetes, por cores diferentes ou pelo posicionamento da legenda na tela. A segunda característica é a explicitação de efeitos sonoros. Sempre que uma campainha soa, uma porta bate ou uma música toca, esse som deve ser descrito em forma de texto, já que o espectador surdo não tem acesso a ele (Selvatini, op. cit.).

Portanto, para que pessoas com deficiência auditiva tenham acesso a diversos materiais audiovisuais, é essencial abordar cada detalhe referente à informação, pois somente fazendo uso desses recursos extras elas serão capazes de um perfeito entendimento da mensagem (Sobre, s.d.).

\section{Competências do tradutor}

Segundo Hurtado Albir (2005, p. 19), “a competência tradutória é um conhecimento especializado, integrado por um conjunto de conhecimentos e habilidade, que singulariza o tradutor e o diferencia de outros falantes bilíngues não tradutores". Dessa maneira, como nem todos têm habilidades e competências para serem médicos, atores, advogados, bailarinos etc., nem 
CABAZ e BELAM, Tradução e acessibilidade: audiodescrição e legendagem para surdos e ensurdecidos como campos de atuação para tradutores

todos têm habilidades e competências para serem tradutores, mesmo que sejam bilíngues. Também Rothe-Neves (2005) defende essa visão, afirmando que o tradutor possui alguma capacidade não compartilhada por quem não é tradutor.

O grupo PACTE, da Universidade Autônoma de Barcelona, tem como um de seus objetivos de estudo um modelo sobre a competência tradutória e sua aquisição. Para o grupo

\begin{abstract}
[...] a competência tradutória é um sistema subjacente de conhecimentos, declarativos e, em maior proporção, operacionais, necessários para saber traduzir, que está composto de cinco subcompetências (bilíngue, extralinguística, conhecimentos sobre tradução, instrumental e estratégica) e de componentes psicofisiológicos. (Hurtado Albir, op. cit., p. 28).
\end{abstract}

Além da subcompetência bilíngue, que está integrada por conhecimentos necessários para a comunicação em duas línguas: conhecimentos pragmáticos, sociolinguísticos, textuais e léxico-gramaticais e que faz com que muitas pessoas se sintam capazes de atuar como tradutoras por possuíla, a autora (op. cit.) cita e define as outras competências anteriormente mencionadas, que são as que mais nos interessam ao analisarmos as atividades de AD e LSE, já que nem sempre as mesmas envolvem duas línguas distintas. O quadro abaixo explicita as demais subcompetências listadas por Hurtado Albir (op. cit.).

\begin{tabular}{|c|l|}
\hline SUBCOMPETÊNCIA & \multicolumn{1}{|c|}{ RELACIONA-SE COM } \\
\hline Extralinguística & $\begin{array}{l}\text { Conhecimentos, essencialmente declarativos, sobre o mundo } \\
\text { em geral e âmbitos particulares: conhecimentos (bi)culturais } \\
\text { e enciclopédicos }\end{array}$ \\
\hline \multirow{2}{*}{ Conhecimentos sobre tradu- } & $\begin{array}{l}\text { Conhecimentos, essencialmente declarativos, sobre os prin- } \\
\text { cípios que regem a tradução (unidade de tradução, tipos de } \\
\text { problemas, processos, métodos e procedimentos utilizados) } \\
\text { e sobre aspectos profissionais (tipos de tarefa e de destinatá- } \\
\text { rio) }\end{array}$ \\
\hline & Conhecimentos, essencialmente operacionais, relacionados \\
\hline
\end{tabular}


CABAZ e BELAM, Tradução e acessibilidade: audiodescrição e legendagem para surdos e ensurdecidos como campos de atuação para tradutores

\begin{tabular}{|c|l|}
\hline Instrumental & $\begin{array}{l}\text { com o uso das fontes de documentação e das tecnologias de } \\
\text { informática e comunicação (TIC) aplicadas à tradução }\end{array}$ \\
\hline Estratégica & $\begin{array}{l}\text { conhecimentos operacionais para garantir a eficácia do } \\
\text { processo tradutório. Tem um caráter central, pois controla o } \\
\text { processo tradutório e serve para: planejar o processo e ela- } \\
\text { borar o projeto tradutório (escolha do método mais adequa- } \\
\text { do); avaliar o processo e os resultados parciais obtidos em } \\
\text { função do objetivo final perseguido; ativar as diferentes } \\
\text { subcompetências e compensar deficiências entre elas; iden- } \\
\text { tificar problemas de tradução e aplicar os procedimentos } \\
\text { para sua resolução } \\
\text { Componentes cognitivos, tais como memória, percepção, } \\
\text { atenção e emoção; aspectos de atitude, como curiosidade } \\
\text { intelectual, perseverança, rigor, espírito crítico, conhecimen- } \\
\text { to e confiança em suas próprias capacidades, conhecimento } \\
\text { do limite das próprias possibilidades, motivação etc.; habili- } \\
\text { dades, tais como criatividade, raciocínio lógico, análise e } \\
\text { síntese etc. }\end{array}$ \\
\hline Componentes psicofisiolá-
\end{tabular}

Tabela 1 - Subcompetências listadas por Hurtado Albir (2005)

O fato de as pessoas acreditarem que a tradução é uma atividade prática, que requer apenas um conhecimento da língua e um bom dicionário, contribui para que ela seja vista como uma atividade menor, pouco reconhecida pelo mercado de trabalho e pelas instituições que requerem serviços de tradução. Porém, a prática da tradução requer competências e estratégias diversas, exigindo uma formação e uma qualificação que fornecem ao tradutor as habilidades e conhecimentos suficientes para um bom desempenho. Outra questão que gera descrédito e desvalorização da profissão de tradutor e que, infelizmente, continua se confirmando devido a trabalhos realizados por pessoas não qualificadas é a falta de qualidade no ato tradutório. Mas, com o desenvolvimento dos estudos na área de tradução, redefinindo a natureza e o objetivo da atividade, mostra-se que é possível se traduzir adequadamente, a partir de uma formação especializada 
CABAZ e BELAM, Tradução e acessibilidade: audiodescrição e legendagem para surdos e ensurdecidos como campos de atuação para tradutores

do tradutor, de seu exercício consciente da profissão e de sua contínua qualificação (Pagano, 2013).

O desempenho de um bom tradutor é bastante dependente de uma situação no tempo e no espaço, já que traduzir não envolve apenas línguas, mas culturas diferentes (Rothe-Neves, op. cit.). Por envolver muitos aspectos além da língua em si e exigir competências específicas do profissional, como as citadas acima, a atividade de tradução não pode ser meramente o transporte ou a transferência de significados de uma língua para outra (Arrojo, 2007).

\section{Legislação profissional nas áreas de acessibilidade audiovisual e tra- dução}

Assim como a profissão de tradutor, que, apesar de reconhecida, não é regulamentada, podendo ser exercida também por pessoas sem formação acadêmica específica em tradução, a AD e a LSE também não exigem formação acadêmica para serem exercidas.

O projeto de lei n. ${ }^{\circ}$ 5.156, de 2013 (Brasil, 2013), feito por Eduardo Barbosa, que dispõe sobre a regulamentação do exercício da profissão de audiodescritor, não define uma formação acadêmica obrigatória para o exercício de tal atividade. Além disso, “a Norma Complementar 01/2006, portaria 310 de junho de 2006, que complementa o decreto 5296 de 2004, não reconhece o status de tradução na legendagem para surdos e nem na audiodescrição para cegos" (Araújo; Vieira; Monteiro, 2013).

Apesar da Norma Complementar acima mencionada, tanto a AD quanto a LSE se enquadram na definição de TAV e na teoria de Jakobson (1959), citada anteriormente, ambas como traduções intersemióticas, podendo ser intra ou interlinguais. Portanto, ambas as atividades podem e devem ter um tradutor envolvido no seu processo de produção devido à congruência entre as mesmas, que será detalhada na Análise e Discussão dos Dados. 
CABAZ e BELAM, Tradução e acessibilidade: audiodescrição e legendagem para surdos e ensurdecidos como campos de atuação para tradutores

\section{Metodologia}

O presente trabalho é de natureza qualitativa, voltada para pesquisar como a acessibilidade e a tradução se inter-relacionam nos dias de hoje, e como o profissional de tradução se insere nesse contexto.

A pesquisa é de cunho bibliográfico e interpretativo/exploratório. Apoiamo-nos em diversos autores para definir conceitos como acessibilidade, AD, LSE e competências do tradutor. Além disso, utilizamos um questionário como instrumento de coleta de dados, respondido por 5 profissionais atuantes nas áreas de AD e/ou LSE, a fim de fazermos um levantamento das características dessas áreas, das competências necessárias para se atuar nas mesmas e dos desafios que os profissionais encontram no diaa-dia. Apoiamo-nos nas respostas das participantes, que foram escolhidas por atuarem de forma bastante ativa nas áreas de AD e/ou LSE, para relacionarmos a prática tradutória com as atividades de AD e LSE. Consideramos que é uma amostra pequena, mas, ressaltamos o fato de serem atividades novas, não tendo muitos profissionais que atuam nas mesmas.

O questionário (Apêndice A) foi dividido em 3 partes: dados pessoais, formação acadêmica e 8 questões específicas sobre as atividades de $\mathrm{AD}$ e LSE, abordando, por exemplo, os principais desafios encontrados pelas profissionais e as competências necessárias para atuar nessas áreas. Por questões éticas, as participantes da pesquisa serão caracterizadas como P1, P2, P3, P4 e P5.

\section{Análise e discussão dos dados}

Começaremos a análise do questionário pelos dados pessoais e acadêmicos das participantes, as quais atuam na área da acessibilidade, desenvolvendo pesquisas, dando cursos e aulas e realizando diversos trabalhos nas áreas de AD e/ou LSE.

P1 tem 44 anos e trabalha como tradutora, audiodescritora e professora. Possui graduação em Letras Tradutor e Intérprete, assim como especialização, mestrado e doutorado voltados, respectivamente, às áreas de tradução, linguística e língua e literatura inglesa; P2 tem 45 anos e trabalha 
CABAZ e BELAM, Tradução e acessibilidade: audiodescrição e legendagem para surdos e ensurdecidos como campos de atuação para tradutores

como professora. É graduada em Letras com bacharelado em Tradutor, mestre em Linguística Aplicada e doutora em Comunicação e Semiótica; P3 tem 34 anos, trabalha como tradutora e professora. É graduada em LetrasTradutor, possui especialização nas áreas de história, ensino de línguas, ética e mestrado em fonoaudiologia; P4 tem 44 anos, trabalha como audiodescritora e é graduada em Publicidade e Propaganda; P5 tem 52 anos, é ex-docente da UFBA (Universidade Federal da Bahia) e trabalha como tradutora audiovisual e audiodescritora freelance. É graduada em Letras com habilitação em Tradução e Interpretação e possui mestrado, doutorado e pós-doutorado, voltados, respectivamente, para Língua e Literatura Inglesas, Letras e Tradução Audiovisual. Com essas informações, podemos ver que a maioria das participantes é graduada em Letras-Tradutor, mostrando que o profissional de tradução está inserido nas atividades de AD e/ou LSE e que esse profissional tem uma bastante influência nessas áreas, visto que as participantes do presente trabalho são grandes pesquisadoras e profissionais, com muita importância nas áreas.

Com um total de 8 questões abertas, que serão analisadas a seguir, o questionário abordou como é o dia-a-dia de um profissional que atua nas áreas de $\mathrm{AD}$ e/ou LSE e quais as competências e habilidades necessárias para realizá-las, a fim de mostrar que o profissional de tradução possui as devidas competências e está totalmente apto a desenvolver essas práticas.

A primeira questão aborda há quanto tempo e como as participantes começaram a atuar na área de acessibilidade. P1 diz que foi há cerca de 6 anos, quando pediram para que ela desse aulas de $\mathrm{AD}$ em um curso de especialização em tradução, exigindo que ela estudasse muito e mergulhasse em diversas vertentes da AD; P2 afirma que atua como docente e pesquisadora na área de tradução desde 1997 e começou a atuar no campo de pesquisas sobre LSE e AD em 2010. Além disso, é coordenadora de um grupo voltado à mídia acessível e TAV; P3 trabalha nessa área há 3 anos e faz parte do grupo coordenado por P2; P4 era publicitária e há 5 anos atua como audiodescritora. Atualmente também faz LSE. A participante relata que em 2010 fez um curso de AD em Porto Alegre e esse foi seu primeiro contato com a área de "acessibilidade comunicacional", expressão que ela costuma usar; e P5 diz que começou a atuar na área em 2002, fazendo pes- 
CABAZ e BELAM, Tradução e acessibilidade: audiodescrição e legendagem para surdos e ensurdecidos como campos de atuação para tradutores

quisa de recepção sobre LSE na UECE (Universidade Estadual do Ceará). Em 2004 fez seu primeiro curso sobre AD na Alemanha e fundou um grupo de pesquisa na UFBA, com o qual desenvolveu várias pesquisas e coordenou projetos em acessibilidade. Dessa maneira, podemos ver que todas as participantes do presente trabalho estão bastante inseridas na área de acessibilidade, tanto no contexto acadêmico, realizando pesquisas, ministrando cursos e palestras, quanto na produção de produtos audiodescritos e/ou legendados.

A questão de número 2 indaga sobre a quantidade de horas dispendidas semanalmente às atividades de AD e/ou LSE e se há muita demanda por esse tipo de trabalho. P2 e P3, por atuarem num grupo de pesquisa, realizam reuniões semanais ou quinzenais, nas quais trabalham e desenvolvem projetos. Além disso, P3 afirma que são destinadas aproximadamente 10 horas semanais individuais para a continuação dos projetos iniciados nas reuniões em grupo. Todos esses projetos são propostos e desenvolvidos pelo grupo, de forma voluntária, não sendo um trabalho remunerado; P1 diz que recebe muitos pedidos de orçamento, mas poucos se concretizam, pois ela insiste por uma condição digna de trabalho, para si e seus colegas; P5 diz que, de 2004 a 2012, realizou diversos trabalhos junto ao grupo que fundou na UFBA e que toda semana recebia, pelo menos, um email com pedido de orçamento. Em 2014, ela deixou a UFBA e mudou-se para a Alemanha, onde muitas atividades acontecem no campo da acessibilidade. Diz que todo pedido de orçamento que recebe agora repassa para o grupo no Brasil; já P4 afirma que as demandas estão crescendo e hoje ela se dedica exclusivamente a essas atividades, trabalhando cerca de 50/60 horas/semana em sua empresa. Ela diz que, no início, procurava as pessoas, mostrava o recurso e oferecia-o, mas hoje, com a instrução normativa da ANCINE (Agência Nacional do Cinema), o edital da Petrobrás - ambas exigindo recursos acessíveis nos projetos que patrocinam -, e o mercado percebendo a importância dos recursos, as demandas têm aumentado e a lógica se inverteu: hoje as pessoas a procuram para fazer orçamento. Apesar de apenas P4 e P5 afirmaram ter bastantes demandas de trabalho que realmente se concretizam, não significa que as demais participantes estejam pouco envolvidas com a área, pois estão em constante pesquisa, participam 
CABAZ e BELAM, Tradução e acessibilidade: audiodescrição e legendagem para surdos e ensurdecidos como campos de atuação para tradutores

de grupos, publicam artigos e difundem as atividades. O que justifica o fato de a demanda por esse tipo de atividade enquanto trabalho remunerado não ser tão significativa para a maioria das participantes é o fato dessa ser uma área relativamente nova no mercado, a qual muitas pessoas ainda não conhecem.

Na questão 3, perguntou-se se elas recebem demandas de $\mathrm{AD}$ e/ou LSE que sejam interlinguais, ou seja, envolvendo duas línguas distintas. P4 afirma que, em alguns momentos, recebe demandas por legendas idiomáticas (ou interlinguais), mas que não aceita, pois o seu foco é outro, trabalhando apenas com tradução intralingual ou "acessibilidade comunicacional", em suas próprias palavras; P1 diz que nunca recebeu demandas como esta. Ela trabalha, no geral, com roteiros de AD para teatro, sendo, portanto, traduções intralinguais; P5 disse que este tipo de demanda era bem menor, pois ela e o grupo se especializaram em AD e legenda em português; já P2 e P3 trabalham com este tipo de demanda nas LSEs, nas quais, às vezes, é necessário verter o conteúdo da fala por serem séries ou filmes estrangeiros. Como podemos analisar, as demandas por traduções interlinguais, pelo menos entre as participantes da pesquisa, ocorrem com muito menos frequência que as intralinguais e são solicitadas somente com a atividade de legendagem. Por mais que produtos estrangeiros também possam ser audiodescritos, as participantes afirmam não receber este tipo de demanda.

As questões 4 e 5 indagam quais contextos (cultural, educacional etc.) mais demandam essas atividades e como elas geralmente são cobradas. P1 diz que trabalha tanto no contexto cultural como no educacional. No primeiro, atua como audiodescritora e no segundo, trabalha na formação de profissionais, ministrando cursos e montando material didático para audiodescritores. Ela diz que não há um valor médio a ser cobrado, pois não existe uma tabela geral na qual os profissionais possam se basear. Isso faz com que cada empresa, grupo ou profissional tenha sua própria tabela; P2 diz que trabalha com os dois contextos no grupo de pesquisa mencionado anteriormente e que todos os produtos audiodescritos ou legendados pelo mesmo são projetos institucionais e voluntários, não exigindo orçamento; P3 afirma que o contexto cultural é o mais requerido. Já sobre o orçamento, mesmo participando do grupo de pesquisa, no qual as atividades 
CABAZ e BELAM, Tradução e acessibilidade: audiodescrição e legendagem para surdos e ensurdecidos como campos de atuação para tradutores

são realizadas de forma voluntária, ela explica que a atividade de AD é fechada com equipes que providenciam recursos sonoros - seja em lugares fechados ou abertos, seja gravação em estúdio ou AD ao vivo - e profissionais que realizarão a narração. Diz que o trabalho pode ser cobrado por hora, variando o valor de acordo com tipo de demanda. Já a atividade de LSE, por não exigir uma equipe, acaba sendo mais barata e cobrada individualmente; P4 afirma que o maior número de demandas certamente são no contexto cultural (produtos e eventos), mas que já trabalhou bastante com adaptação de material didático. Sobre o orçamento, diz que é complicado falar sobre isso, pois ainda não existe uma tabela de referência a ser seguida no país. Para o cinema, ela diz que existe um indicativo e que geralmente cobra-se por minuto. Já para teatro e exposição de arte, por exemplo, depende muito do produto, pois cada um tem sua especificidade e vai demandar um tipo de orçamento diferente; P5 diz que realizava essas atividades principalmente para produtores de cinema independentes e instituições educacionais que têm enfoque na acessibilidade. Ela estipulou um patamar que achava justo dentro do mercado, mas cada profissional cobra o quanto quer, já que não são atividades regulamentadas. A partir disso, podemos perceber que a maior parte dos produtos audiodescritos se encontra no contexto cultural, pois a maioria das participantes afirmou trabalhar mais com este tipo de produto. Já na questão do orçamento, analisamos que a criação de uma tabela de referência seria de grande importância para as áreas, já que todas afirmaram não existir um valor médio a ser cobrado, fazendo com que cada profissional cobre o quanto quiser. Como são atividades novas, não regulamentadas, que ainda estão em formação, muitas pessoas não capacitadas oferecem o serviço sem ter o preparo e as competências necessárias, cobrando valores muito menores do que um profissional qualificado, fato que dificulta a atuação do mesmo. Essa questão atinge a tradução de um modo geral, por não ser uma profissão regulamentada.

A sexta questão aborda as competências necessárias para um profissional atuar nas áreas de AD e LSE. P1 afirma que o audiodescritor deve ser atento aos detalhes, ler muito, ter um bom texto, gostar de pesquisar e de conhecer coisas novas, além de ser sensível, estar aberto a críticas e ouvir seu público; P2 diz que o profissional deve ter conhecimento teórico em 
CABAZ e BELAM, Tradução e acessibilidade: audiodescrição e legendagem para surdos e ensurdecidos como campos de atuação para tradutores

tradução, TAV, cinema, linguagem audiovisual, artes, competência linguística em português e conhecimento técnico de alguns softwares e técnicas de legendagem e AD; P3 afirma que para $\mathrm{AD}$ são necessárias várias habilidades, principalmente na produção do roteiro - que é, principalmente, onde o tradutor se insere, já que a narração pode ser feita por um ator, por exemplo. Já para a LSE, a participante afirma que o profissional deve conhecer as técnicas de velocidade da legenda, tipo de cor, número de caracteres, sincronia com a fala e a escrita e segmentação da legenda (quebra de linha); P4 diz que a primeira coisa que ela considera mais importante é a capacitação, pois este é um serviço sério, especializado, e que não deve ser feito por qualquer pessoa. Depois vem a paixão, uma competência que parte para o lado emocional. Segundo ela, temos que ser apaixonados e ativistas nessa área. Como roteirista de $\mathrm{AD}, \mathrm{P} 4$ afirma que é preciso ter o domínio da língua para que se consiga fazer um roteiro. Também é necessário ter capacidade de observação, "reaprendendo a enxergar", observando todos os detalhes do que vai ser audiodescrito. Além disso, deve-se ter uma organização lógica do raciocínio e capacidade de sintetizar o conteúdo, pois não se pode cansar o público com informações irrelevantes. Então, para isso, é necessário fazer um estudo profundo da obra, de forma que o público com deficiência tenha acesso a todas as informações essenciais. Além disso, deve-se estudar muito. P4 afirma que, do total de horas que dedica ao seu trabalho, metade é destinada aos estudos. Com o tempo, ela diz ter aprendido e desenvolvido habilidades na gestão do negócio, como: capacidade de relação interpessoal, contato com o público, humildade para aprender com quem está há mais tempo no mercado e disponibilidade de estar estudando o tempo todo, sempre querendo aprender mais. Já sobre LSE, P4 diz que começou a trabalhar com esta atividade há pouco e que sente falta de uma especialização em tradução para realizar este serviço com mais segurança; P5 afirma que, em primeiro lugar, o profissional deve fazer um curso em tradução, pois AD e LSE são atividades que pertencem aos estudos dessa área. Em segundo, ter alguma formação em artes visuais ou audiovisuais, sendo sensível à obra que será audiodescrita ou legendada, sabendo "ler" essa obra melhor do que uma pessoa que não é da área. E, em terceiro lugar, o profissional deve saber escrever muito bem em português. 
CABAZ e BELAM, Tradução e acessibilidade: audiodescrição e legendagem para surdos e ensurdecidos como campos de atuação para tradutores

O Gráfico 1 mostra as principais competências listadas pelas participantes da pesquisa e indica, em porcentagem, a ocorrência de cada uma, ou seja, quantas das 5 participantes a mencionaram, sendo $100 \%$ referente ao total, $80 \%$ referente a 4 participantes e assim por diante.

\section{COMPETÊNCIAS}

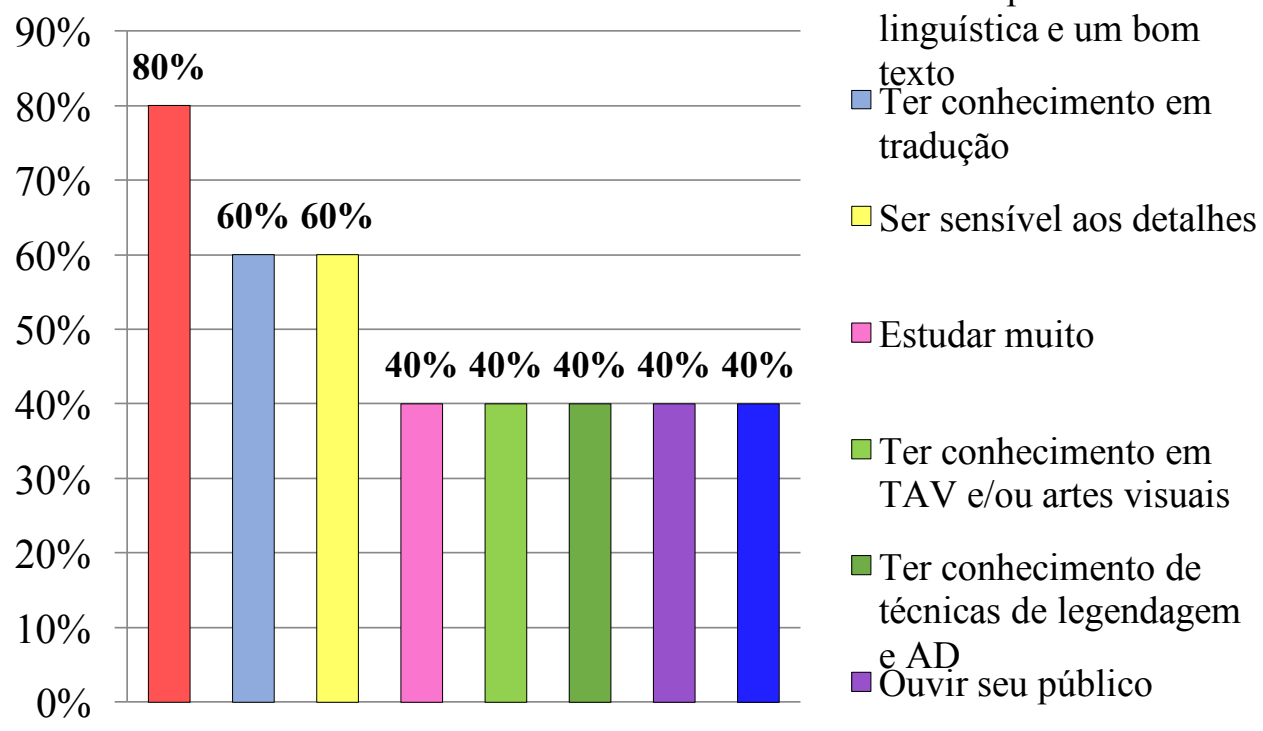

Gráfico 1 - Gráfico das competências necessárias para atuar nas áreas de AD e/ou LSE, listadas pelas participantes.

Todas as competências mencionadas se relacionam com as subcompetências definidas por Hurtado Albir (2005). As mais citadas são: ter competência linguística e um bom texto $(80 \%)$, ter conhecimento em tradução (60\%) e ser sensível aos detalhes (60\%). A primeira, citada por 4 das 5 participantes, diz respeito a aspectos da subcompetência bilíngue, a respeito da qual Hurtado Albir (op. cit.) afirma se tratar de conhecimentos pragmáticos, sociolinguísticos, textuais e léxico-gramaticais de todas as línguas envolvidas no processo. No caso da AD e da LSE, como vimos anteriormente, essa competência deve estar presente, principalmente, no português, já que, na maioria das vezes, as demandas são de traduções intralinguais, pelo menos para as participantes da pesquisa. As outras duas principais competências - ter conhecimento em tradução e ser sensível aos detalhes - citadas 
CABAZ e BELAM, Tradução e acessibilidade: audiodescrição e legendagem para surdos e ensurdecidos como campos de atuação para tradutores

por 3 participantes, inserem-se, respectivamente, na subcompetência de conhecimentos sobre a tradução e nos componentes psicofisiológicos. $\mathrm{Na}$ definição de Hurtado Albir (op. cit.), a primeira é composta por conhecimentos sobre os princípios que regem a tradução e sobre aspectos profissionais. Já a segunda, seriam componentes cognitivos, como memória, percepção, atenção e emoção. Todas as demais competências, citadas por, pelo menos, 2 participantes, também se enquadram no conceito das subcompetências listadas por Hurtado Albir (op. cit.). São elas: estudar muito (40\%), que relaciona-se à subcompetência extralinguística, que é composta por conhecimentos sobre o mundo, (bi)culturais e enciclopédicos, assim como aos componentes psicofisiológicos - citados anteriormente, envolvidos no ato de estudar; ter conhecimento em TAV e/ou artes visuais (40\%), relacionada com a subcompetência de conhecimento de tradução - citada anteriormente; ter conhecimento de técnicas de legendagem e AD (40\%), envolvendo aspectos da subcompetência instrumental, que consiste em conhecimentos relacionados com o uso das fontes de documentação e das tecnologias de informática e comunicação aplicadas à tradução; ouvir seu público (40\%), relacionando-se com a subcompetência estratégica, que é composta de conhecimentos operacionais para garantir a eficácia do processo tradutório. Além disso, temos a questão da capacitação (40\%), que está relacionada com a teoria de Pagano (2013) sobre a prática da tradução, que afirma que a mesma requer competências e estratégias diversas, exigindo uma formação e uma qualificação que fornecem ao tradutor as habilidades e conhecimentos suficientes para um bom desempenho.

Com todas essas informações, podemos ver que as competências tradutórias são completamente congruentes com as competências necessárias a um profissional que atua nas áreas de AD e/ou LSE. Além das competências linguísticas, essenciais para um profissional de tradução, as participantes mencionam todas as outras subcompetências listadas por Hurtado Albir (op. cit.): extralinguística, conhecimentos sobre tradução, instrumental, estratégica, e componentes psicofisiológicos. Na área de LSE, o profissional graduado em cursos de Tradutor já possui boa parte das técnicas indicadas pela P3, pois a legenda aberta - destinada ao público ouvinte - já é 
CABAZ e BELAM, Tradução e acessibilidade: audiodescrição e legendagem para surdos e ensurdecidos como campos de atuação para tradutores

realizada por tradutores e, geralmente, é uma das disciplinas ensinadas nos cursos de Tradutor, exigindo esses mesmos tipos de conhecimento.

A pergunta de número 7 questiona quais as principais dificuldades e desafios encontrados por essas profissionais ao atuarem nessas áreas. P1 diz que a primeira grande dificuldade é a falta de conhecimento dos clientes sobre os recursos, fazendo com que não entendam o valor do serviço. A segunda questão é a falta de profissionais na área. Isso faz com que muitas vezes ela perca um trabalho por não ter um número maior de audiodescritores ou por não poder estar em dois ou três lugares ao mesmo tempo para realizar trabalhos que coincidem. Já os desafios são: não conhecer o perfil do público alvo, por não existir um perfil demográfico detalhado da pessoa com deficiência. Sendo assim, é difícil modalizar seu texto se você não sabe a quem ele se destina; ela também cita o fato de estudar muito, incessantemente, para se superar a cada dia; P2 afirma que os principais desafios são: pensar em recursos para pessoas com deficiência, seja visual ou auditiva, tendo que estudar os principais parâmetros, fazer escolhas precisas para cada gênero do produto cultural ou acadêmico e buscar consultorias de especialistas na área e de pessoas com deficiência; outro desafio é o fato de trabalhar de forma coletiva, realizando a produção do roteiro, depois o ensaio das locuções e revisão das LSEs; P3 diz que uma das principais dificuldades no grupo do qual participa é a consultoria por parte de pessoas com deficiência e a aprovação do resultado mediante a pesquisa. Quanto aos desafios, ela afirma que é necessária uma postura imparcial e que realmente faça parte do contexto das pessoas com deficiência auditiva e visual, conseguindo transpor os significados dos signos de um meio para o outro, preservando a obra original. Outro ponto citado por ela é que no Brasil, tanto os estudos quanto as práticas e políticas de acessibilidade, ainda caminham a passos lentos, provocando limitações na área; P4 diz que a dificuldade de conseguir demandas já não existe mais, pois hoje as pessoas é que vêm procurá-la. Mas a dificuldade que encontra agora é a de convencer as pessoas a manterem uma agenda regular de ofertas de atrações e materiais com o recurso de acessibilidade comunicacional. Outra grande dificuldade citada, já mencionada por outra participante e que vem crescendo nesse mercado, é o fato de existirem pessoas despreparadas atuando na 
CABAZ e BELAM, Tradução e acessibilidade: audiodescrição e legendagem para surdos e ensurdecidos como campos de atuação para tradutores

área, achando que "é só chegar e descrever" e cobrando por um serviço profissional que elas não podem prestar, por não terem a capacitação necessária. Outras muitas seriam: convencer as pessoas da importância do recurso, tendo, muitas vezes, que convencer a própria pessoa com deficiência, pois essas pessoas não estão acostumadas a saírem de casa para irem ao cinema, ao teatro, a uma exposição de arte. P4 diz que por acontecer mesmo que poucas vezes - de organizar um evento acessível e aparecerem poucas pessoas com deficiência, aprendeu que tinha que dar um reforço no processo de divulgação para incentivar essas pessoas a conhecerem o desconhecido; P5 afirma, assim como outras participantes, que as duas principais dificuldades são: clientes que não querem pagar por qualidade e pessoas que se dizem profissionais e cobram um valor bem mais baixo, causando a desqualificação da área.

O Gráfico 2, no mesmo padrão do anterior, mostra mais claramente as principais dificuldades mencionadas pelas participantes:

\section{DIFICULDADES}

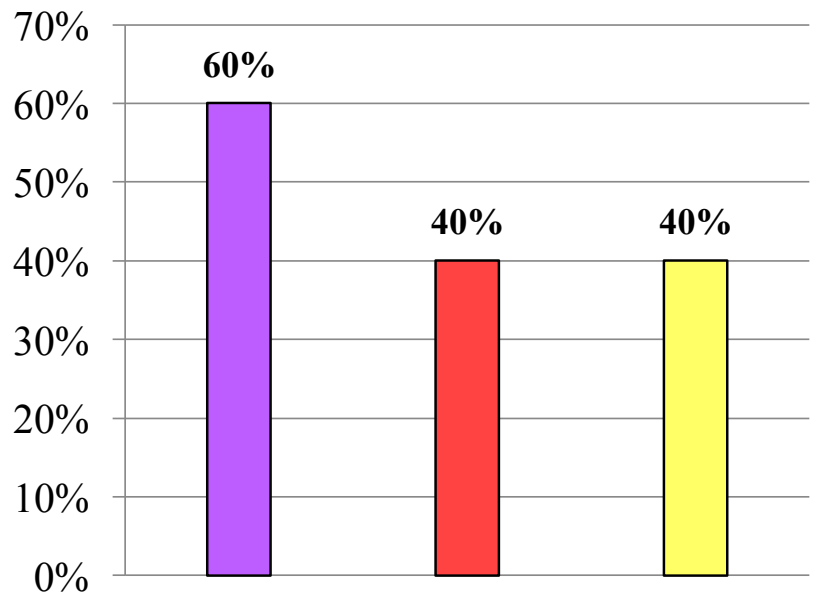

$\square$ Pessoas não qualificadas oferecendo o serviço

$\square$ Clientes que não entendem o recurso e não querem pagar por qualidade

口Adaptação do produto à realidade de pessoas com deficência

Gráfico 2 - Gráfico das principais dificuldades encontradas nas áreas de AD e/ou LSE, listadas pelas participantes. 
CABAZ e BELAM, Tradução e acessibilidade: audiodescrição e legendagem para surdos e ensurdecidos como campos de atuação para tradutores

Podemos analisar, através das respostas das participantes, que as dificuldades encontradas por elas são praticamente as mesmas: pessoas despreparadas oferecendo serviço na área e cobrando muito menos que um profissional qualificado, o que desvaloriza o serviço (60\%). O mesmo acontece na profissão de tradutor, pois a falta de qualidade no ato tradutório, infelizmente continua se confirmando devido a trabalhos realizados por pessoas não qualificadas e que aumentam a desvalorização da área (Pagano, 2013). Assim como citado anteriormente, "nem todo mundo possui a competência tradutória [...] sendo, portanto, um conhecimento especializado" (Hurtado Albir, 2005, p. 28, grifo da autora), isso também se aplica às atividades de AD e na LSE, que exigem capacitação e as mesmas competências exigidas de um profissional de tradução, como pudemos observar pelas respostas das participantes. A desvalorização que existe na profissão de audiodescritor, em que as pessoas pensam que "é só chegar e descrever", como citado por P4, também existe na profissão de tradutor, pois, como dito por Pagano (2013), as pessoas acreditam que é necessário apenas o conhecimento da língua e um bom dicionário para realizar uma tradução. Além disso, outra principal dificuldade citada por elas é o fato de muitos clientes não entenderem a complexidade do recurso e também a necessidade de profissionais qualificados que devem receber um valor justo por esse serviço $(40 \%)$. A última das principais dificuldades apontadas pelas participantes é a questão da adaptação dos produtos à realidade de pessoas com deficiência (40\%). Essa também é uma dificuldade encontrada pelo profissional de tradução, pois é necessário possuir as subcompetências extralinguística e estratégica definida por Hurtado Albir (op. cit.). É necessário conhecer seu público alvo, o mundo que o cerca, para, assim, fazer com que ele entenda da melhor maneira possível o conteúdo do produto audiodescrito ou legendado. Em qualquer tradução, a questão de conhecer seu público alvo é de extrema importância para que o produto final seja satisfatório.

A oitava e última questão trata de leis de acessibilidade e da inclusão das pessoas com deficiência na sociedade, questionando se elas acreditam que o cenário que encontramos hoje, onde muitas pessoas ainda não conhecem os recursos de AD e LSE, tende a mudar. As participantes afir- 
CABAZ e BELAM, Tradução e acessibilidade: audiodescrição e legendagem para surdos e ensurdecidos como campos de atuação para tradutores

mam que o cenário já mudou bastante e está mudando cada vez mais, sendo a acessibilidade obrigatória em muitos meios, alcançando cada vez mais pessoas. P1 diz que a principal maneira de alcançar mudanças é pela conscientização dos usuários, fazendo com que entendam seus direitos e exijam. Também acredita que a divulgação do que é e para o que serve AD e LSE para o público em geral é uma maneira de mudar o cenário; P2 diz que, apesar de muitas pessoas não terem ouvido falar sobre esses recursos, eles são obrigatórios, fruto da luta de muitas pessoas. Ela acredita que, aos poucos, os brasileiros entenderão que as pessoas com deficiência possuem o direito de frequentar salas de cinema, teatro, ambientes culturais com acessibilidade, que eles se acostumarão com as pessoas nesses ambientes e isso será, finalmente, a inclusão. Outro ambiente onde ela afirma já existir bastante mudança é o acadêmico, que tem cada vez mais palestras, cursos, oficinas e disciplinas sobre acessibilidade e, aos poucos, formando mais profissionais capacitados para atuarem nessas áreas; P3 acredita que a possibilidade de mudança é grande, já que existe uma legislação a ser cumprida até 2016, com a ampliação das horas com legenda oculta para a grade total dos programas televisivos. Porém, sabe-se que a legislação existe, mas é necessário que haja fiscalização para que seja cumprida; P4 afirma que é necessária uma construção coletiva: o poder público entender que a lei precisa ser cumprida; os produtores culturais - e o público - entenderem que é preciso colocar esse recurso nos eventos e nos produtos; e convencer as pessoas que se interessam pela área de que é preciso muito estudo, muita dedicação, pois é um trabalho muito sério, de enorme responsabilidade. Segundo P4, esta é uma "revolução da inclusão pela acessibilidade"; e P5 diz que o Brasil já avançou muito e que morando na Europa percebe que os profissionais enfrentam os mesmos problemas. Ela diz que o principal entrave são as redes de televisão que não querem pagar por qualidade e insistem em empregar pessoas desqualificadas, mas que a pressão está cada vez maior. P5 afirma que algo que ajudaria seria o feedback dos usuários, mas que não basta ser cego ou surdo para falar sobre AD ou LSE; então, seria interessante, na opinião dela, que os cursos de formação incluíssem esse público, para que o feedback fosse dado por pessoas com deficiência que possuem certificado em AD e/ou LSE. Finalizando, então, nossa análise, 
CABAZ e BELAM, Tradução e acessibilidade: audiodescrição e legendagem para surdos e ensurdecidos como campos de atuação para tradutores

podemos ver que as participantes acreditam que o cenário mudou e vai mudar cada vez mais e que pesquisar muito, conscientizar o público com e sem deficiência e os órgãos públicos seriam alternativas essenciais para garantir uma mudança e acessibilidade cada vez maiores.

\section{Considerações finais}

O objetivo principal do presente trabalho foi fazer um levantamento das principais características das atividades de AD e LSE, assim como analisar as competências necessárias para se atuar nessas áreas e os desafios encontrados no dia-a-dia do profissional, a fim de relacionar a prática da tradução com ambas as atividades mencionadas e verificar quais as competências necessárias para o tradutor estar apto a trabalhar com as mesmas.

Através de uma revisão bibliográfica das atividades de AD e LSE e dos estudos da tradução, além do questionário enviado a 5 profissionais que trabalham com essas atividades, fizemos uma análise, relacionando as atividades à tradução. Apesar de ser uma amostra pequena, ressaltamos o fato de serem ambas as áreas serem novas, portanto ainda não existem muitos profissionais atuam nas mesmas.

Após análise das respostas dadas pelas participantes, percebemos que a maioria delas é graduada em Letras-Tradutor e que todas estão bastante inseridas na área de acessibilidade, tanto no contexto acadêmico, realizando pesquisas, ministrando cursos e palestras, quanto na produção de produtos e eventos acessíveis, o que mostra que o profissional de tradução já atua e tem grande importância nessas atividades, visto que as profissionais entrevistadas realizam trabalhos muito importantes para a área. Além disso, as dificuldades listadas pelas participantes e as dificuldades encontradas por profissionais de tradução são bem parecidas, o que aproxima ainda mais as práticas. E o mais importante, que nos permitiu fazer uma associação direta entre as atividades de acessibilidade e tradução, foram as competências necessárias para se atuar nas áreas de AD e LSE citadas pelas participantes, que são congruentes às competências tradutórias, principalmente as subcompetências definidas por Hurtado Albir (2005): bilíngue, extralinguística, conhecimentos sobre tradução, instrumental, estratégica e componentes psicofisiológicos. 
CABAZ e BELAM, Tradução e acessibilidade: audiodescrição e legendagem para surdos e ensurdecidos como campos de atuação para tradutores

Dessa maneira, pudemos observar que o profissional de tradução possui as competências necessárias e está apto a desenvolver as atividades de AD e LSE. Ressaltamos o fato de que não tiramos o mérito dos demais profissionais especialistas em linguagem que realizam essas atividades, apenas buscamos mostrar a congruência entre a prática tradutória e as atividades de AD e LSE, sendo mais uma área onde tradutores podem se especializar e atuar. Ambas as atividades são congruentes com os estudos da tradução e acreditamos que deveriam ser mais estudadas, a partir dessa perspectiva, no sentido de contribuir para uma maior atuação do profissional de tradução nessa área, e para uma maior divulgação das atividades de AD e LSE, com vistas ao aumento da acessibilidade e inclusão social.

\section{Referências}

ACESSIBILIDADE. Secretaria Nacional de Promoção dos Direitos da Pessoa com Deficiência, s.d. Disponível em: $<$ http://www.pessoacomdeficiencia.gov.br/app/acessibilidade-0>. Acesso em: 4 jun. 2015.

ARAÚJO, V. L. S.; VIEIRA, P. A.; MONTEIRO, S. M. M. Legendagem para surdos e ensurdecidos (LSE): Um estudo de recepção com surdos da região Sudeste. TradTerm, São Paulo, v. 22, p. 283-302, dez. 2013.

ARROJO, R. Oficina de tradução: a teoria na prática. 5.ed. São Paulo: Ática, 2007.

BRASIL. Projeto de Lei no 5.156, 2013. Dispõe sobre a regulamentação do exercício da profissão de audiodescritor. Disponível em: $<$ http://www2.camara.leg.br/proposicoesWeb/prop_mostrarintegra;jsession id=D02F497ED7908A6EE5955C7E0E6D41A1.node1?codteor=1073586\&filen ame=Avulso+-PL+5156/2013>. Acesso em: 5 jun. 2015.

BRASIL. Ministério das Comunicações. Portaria no 310, de 27 de junho de 2006. Portaria que aprova a Norma no 001/2006 - Recursos de acessibilidade, para pessoas com deficiência, na programação veiculada nos serviços de radiodifusão de sons e imagens e de retransmissão de televisão. Disponível em: <http://www.mc.gov.br/portarias/24680-portaria-n-310-de-27-dejunho-de-2006>. Acesso em: 5 jun. 2015.

FRANCO, E. Audiodescrição. Tradução audiovisual e acessibilidade, 29 set. $2008 . \quad$ Disponível em: <http://www.acessibilidadeaudiovisual.blogspot.com.br/2008/09/audiodesc rio.html>. Acesso em: 4 jun. 2015. 
CABAZ e BELAM, Tradução e acessibilidade: audiodescrição e legendagem para surdos e ensurdecidos como campos de atuação para tradutores

FRANCO, E. P. C.; ARAÚJO, V. L. S. Questões terminológico-conceituais no campo da tradução audiovisual (TAV). Tradução em Revista, Rio de Janeiro, n. 11, 2. sem. 2011. Disponível em: <http://www.maxwell.vrac.pucrio.br/18884/18884.PDFXXvmi=fuvrLgj28O9KLjfSQt9zb6aLZno638DjEaLqq 6tAVDkHWBBN5LngRx2RWrx0ACkfM6GedaP9NbRLMtzSfW98vc0sFZtf BOuoVcE9mtjbFcWrHwlWuu61I7un60EIPa8LmMVJggUWsSpapL8UhfW1 msots4diel5C92lqihnMbNxBz7wRmtSKxifrmsLCPQeZTBqcTO05DZHd6e5 tJxeHhu9ExUhOMwOG8fT34T8ISPV041tN0JvheFWdBf2nMQ4U>. Acesso em: 5 jun. 2015.

FRANCO, E. P. C.; SILVA, M. C. C. C. da. Audiodescrição: breve passeio histórico. In: MOTTA, L. M. V. de M.; ROMEU FILHO, P. (Org). Audiodescrição: transformando imagens em palavras. São Paulo: Secretaria dos Direitos da Pessoa com Deficiência do Estado de São Paulo, 2010. p. 23-42.

GIL, M. Acessibilidade, inclusão social e desenho universal: tudo a ver. Bengala Legal, 22 out. 2006. Disponível em: $<$ http://www.bengalalegal.com/martagil >. Acesso em: 19 nov. 2015.

GORLÉE, D. L. Semiotics and the problem of translation. Amsterdam: Editions Rodopi, 1994.

HURTADO ALBIR, A. A aquisição da competência tradutória: aspectos teóricos e didáticos. In: PAGANO, A.; MAGALHÃES, C. M.; ALVES, F. (Org.). Competência em tradução: cognição e discurso. Belo Horizonte: Editora UFMG, 2005. p. 19-57.

IBGE. Censo Demográfico 2010: características gerais da população, religião, e pessoas com deficiência. Rio de Janeiro: Instituto Brasileiro de Geografia e Estatística, 2010. Disponível em: $<$ http://biblioteca.ibge.gov.br/visualizacao/periodicos/94/cd_2010_religiao_ deficiencia.pdf $>$. Acesso em: 5 jun. 2015.

JAKOBSON, R. On Linguistic Aspects of Translation. In: BROWER, R. A. (Ed.). On Translation. Cambridge, Massachusetts: Harvard University Press, 1959. p. 232-239.

MOTTA, L. M. V. de M. Audiodescrição: recurso de acessibilidade para a inclusão cultural das pessoas com deficiência visual. Planeta Educação, 25 jul. 2008. Disponível em: $<$ http://www.planetaeducacao.com.br/portal/artigo.asp?artigo=1210>. Acesso em: 26 ago. 2015.

MOTTA, L. M. V. de M.; ROMEU FILHO, P. (Org). Audiodescrição: transformando imagens em palavras. São Paulo: Secretaria dos Direitos da Pessoa com Deficiência do Estado de São Paulo, 2010.

NEVES, J. Audiovisual Translation: Subtitling for the Deaf and Hard-ofHearing. 2005. 357 f. Dissertação (Doutorado) School of Arts, Roehampton University, Londres, 2005. 
CABAZ e BELAM, Tradução e acessibilidade: audiodescrição e legendagem para surdos e ensurdecidos como campos de atuação para tradutores

O QUE é audiodescrição. Audiodescrição, s.d. Disponível em: $<$ http://audiodescricao.com.br/ad/o-que-e-audiodescricao/>. Acesso em: 4 jun. 2015.

PAGANO, A. Crenças sobre a tradução e o tradutor: revisão e perspectivas para novos planos de ação. In: PAGANO, A.; MAGALHÃES, C.; ALVES, F. Traduzir com autonomia: estratégias para o tradutor em formação. São Paulo: Contexto, 2013. p. 9-28.

ROTHE-NEVES, R. A abordagem comportamental das competências: aplicabilidade aos estudos da tradução. In: PAGANO, A.; MAGALHÃES, C. M.; ALVES, F. (Org.). Competência em tradução: cognição e discurso. Belo Horizonte: Editora UFMG, 2005. p. 91-107.

SELVATINI, C. Um breve panorama da legenda fechada para surdos e ensurdecidos. Tradução em Revista, Rio de Janeiro, n. 11, 2. sem. 2011. Disponível em:

$<$ http://www.maxwell.vrac.pucrio.br/18849/18849.PDFXXvmi=n2ve0T2iTLuSWK7IoS6UjFb9WPM0WzNlB kA-

BeCT9np2la95A2bvmQHwOwjOuSDRuxs6c61muqoQCzVdB8JZ0qvOZQD tJhmffPmsVnPqPfisOeGqnppnRWcQN-

Qkx8INoxaStzJVpZeSOtAfR1GfSDsJqk5ZtNNSlxMQxvMxv2RkvrBoshFm U96mtcmx0aRm9EdHb1FI4x4A0F0tWFQSPxfjaChaMaxVPLE1NkKRSOsSt tnqafk0dAjndCz0M7WCTC>. Acesso em: 6 jun. 2015.

SOBRE. CPL: soluções em acessibilidade, s.d. Disponível em: $<$ http://www.cplcc.com.br/aboutus.php>. Acesso em: 12 jun. 2015.

Resumo: O presente trabalho tem por objetivo fazer um levantamento das principais características das atividades de audiodescrição (AD) e legendagem para surdos e ensurdecidos (LSE), assim como analisar as competências necessárias para se atuar nessas áreas e os desafios encontrados no diaa-dia do profissional, a fim de relacioná-las com a prática tradutória. Após a análise de um questionário, observou-se que as competências necessárias para atuar nas áreas de AD e LSE e as dificuldades apontadas pelas participantes da pesquisa são congruentes com as competências e dificuldades existentes na prática tradutória.

Palavras-chave: Tradução. Acessibilidade. Audiodescrição. Legendagem para surdos e ensurdecidos. 
CABAZ e BELAM, Tradução e acessibilidade: audiodescrição e legendagem para surdos e ensurdecidos como campos de atuação para tradutores

\begin{abstract}
This study aims to survey the main characteristics of audiodescription (AD) and subtitling for the deaf and hard-of-hearing (SDH) as well as analyze the necessary competences to act in these areas and the challenges found in the professional's daily routine, in order to relate translation to both mentioned activities. After the analysis of a questionnaire, we observed that the competences necessary to act in the areas of AD and SDH and the difficulties mentioned by the participants of this study are congruent with the competences and difficulties found in translation.
\end{abstract}

Keywords: Translation. Accessibility. Audiodescription. Subtitling for the deaf and hard-of-hearing. 
CABAZ e BELAM, Tradução e acessibilidade: audiodescrição e legendagem para surdos e ensurdecidos como campos de atuação para tradutores

\section{Apêndice}

\section{Questionário}

As informações coletadas por meio deste questionário serão utilizadas na elaboração de meu artigo científico de conclusão do curso de LetrasTradutor da Universidade do Sagrado Coração - Bauru - SP, intitulado “Tradução e acessibilidade: audiodescrição e legendagem para surdos e ensurdecidos como campos de atuação para tradutores", sob orientação da Prof. - Dra. Patrícia Viana Belam. Por gentileza, responda a todas as perguntas de forma completa. Sua contribuição é de grande importância para a fase exploratória deste estudo. Obrigada por sua colaboração!

Dados Pessoais

Nome:

Data de nascimento:

Nacionalidade:

Profissão:

Formação Acadêmica

Graduação

Curso: Instituição:

Pós-Graduação

Especialização:

Curso: Instituição:

Mestrado:

Curso: Instituição:

Doutorado:

Curso: Instituição: 
CABAZ e BELAM, Tradução e acessibilidade: audiodescrição e legendagem para surdos e ensurdecidos como campos de atuação para tradutores

Questões específicas sobre sua atuação profissional como tradutor na área da acessibilidade - audiodescrição e/ou legenda para surdos e ensurdecidos:

1. Há quanto tempo e como você começou a atuar na área da acessibilidade?

2. Você tem muita solicitação por trabalhos nessa área? Aproximadamente quantas horas semanais/mensais são destinadas às atividades de audiodescrição e/ou legenda para surdos e ensurdecidos?

3. Dentro dessas atividades, que se caracterizam como traduções intersemióticas, você recebe também solicitações por trabalhos que sejam, ao mesmo tempo, interlinguais?

4. Quais são os contextos que mais te demandam essas atividades (cultural, educacional, etc)?

5. Como essas atividades são geralmente cobradas? Existe um valor médio para as mesmas?

6. Quais as competências necessárias para um profissional atuar nas áreas de audiodescrição e/ou legenda para surdos e ensurdecidos?

7. Quais as principais dificuldades e desafios encontrados pelos profissionais que atuam nessas áreas?

8. Mesmo com as leis existentes para que pessoas com deficiência visual e auditiva tenham acesso aos diversos meios de comunicação, à educação e à cultura, ainda não temos um cenário muito acessível e muitas pessoas nunca ouviram falar sobre as atividades de audiodescrição e legenda para surdos e ensurdecidos. Você acredita que esse cenário tende a mudar? De que maneira? 